\title{
Anemia aplástica pós-viral: Relato de caso
}

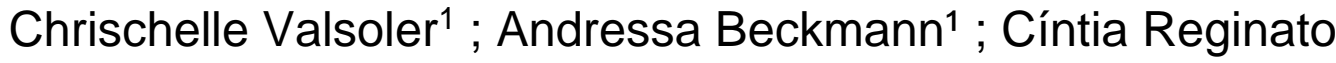 \\ Martins ${ }^{1}$; Gabrielle Delazeri1 ; Raíssa Bianchini ${ }^{1}$; Denise Ramos de \\ Almeida $^{2}$
}

\section{Resumo}

A Anemia aplástica é uma doença crônica, rara e de alta letalidade caracterizada por algum grau de pancitopenia e hipocelularidade acentuada na medula óssea. O diagnóstico diferencial com doenças que também cursam com pancitopenia é indispensável. Bem como, a busca pelo fator causal. O tratamento é o transplante de medula óssea quando o paciente tem menos de 40 anos e possui doador HLA compatível ou imunossupressores. O prognóstico é relativo e tende a ser melhor quando o transplante de medula óssea é feito com doador HLA idêntico.

Palavras Chave: pancitopenia; distúrbio de coagulação; Aplasia de medula

${ }^{1}$ Graduando do curso de Medicina da Universidade de Passo Fundo, chr1s.v@hotmail.com

2 Professora Curso Medicina Hematologia/Hemoterapia na Universidade de Passo Fundo, Mestra em Bioexperimentação, Coordenadora Residencia Médica Hematologia/Hemoterapia HSVP/UFFS, denisedeal@hotmail.com 


\section{Introdução}

A anemia aplástica (AA) ou aplasia de medula é uma doença crônica e rara, com alta letalidade, com escassa literatura médica em população brasileira. É caracterizada por pancitopenia moderada ou grave periférica e com hipocelularidade acentuada na medula óssea.

As causas de AA podem ser congênitas ou adquiridas. Dentre as causas adquiridas estão o uso de medicamentos, infecções ativas, neoplasias hematológicas, invasão medular por neoplasias não hematológicas, doenças sistêmicas e exposição a radiação e agentes químicos.

Este relato tem por objetivo descrever caso de AA pós viral.

\section{Relato de caso}

Feminino, 24 anos, advogada, procurou atendimento médico na emergência do Hospital São Vicente de Paulo - HSVP devido a lesões orais sangrantes iniciadas há 48 horas, progressivas. No momento da consulta, com sufusões petequiais. Acompanhado de hematúria e epistaxe, dores articulares e astenia. Sem febre. Relatava quadro de Paralisa do VII par Craniano precedido por dor auricular (Paralisia de Bell) sendo que fez uso de aciclovir e prednisona. Paciente previamente hígida. Ao Exame físico com mucosas hipocoradas 2/4, petéquias generalizadas e equimoses, sem linfonodomegalia ou hepatoesplenomegalia. Exames da origem: Plaquetas 26.900; hemoglobina 13,5; hematócrito 40; leucócitos 6590. Sorologias virais negativas. Laboratório da Emergência: Plaquetas 1.000; leucócitos 1.390, bastonetes 13,9; segmentados 1.000; hemoglobina 8,1 ; hematócrito $24 \%$; tempo de protrombina 13,9 ; ativ $73,9 \%$; relação normalizada internacional 1,7 ; tempo de tromboplastina parcial ativada 23 ; velocidade de sedimentação globular 19; reticulócitos $0,1 \%$; ureia 17 ; creatinina 0,6 ; aminotransferase de aspartato 69; aminotransferase de alanina 74; Desidrogenase lática 407; Bilirrubina total 2,45; Bilirrubina direta 0,7; Bilirrubina indireta 1,74. Radiografia de tórax normal. Medulograma: hipocelular, alguns linfócitos esparsos, sem eritro ou megacariócitos presentes e Imunofenotipagem: linfócitos ativados, sem blastos. Patologia da Biópsia Medular: Aplasia. Sem irmãos para possível Transplante de Medula Aparentado. Indicado Protocolo para AA com Corticoide, Ciclosporina enquanto aguarda Imunoglobulina Antitimócitos (coelho). Intercorrências infecciosas e necessidade transfusional frequentes. Atualmente aguardando HLA classe II para Transplante não Aparentado ou mesmo Hapótiplo (mãe). Fez uso de inúmeros antibióticos. Arpergilose pulmonar invasiva em tratamento com voriconazol. 


\section{Discussão}

Na suspeita clínica de AA é necessário para diagnóstico hemograma completo com contagem de reticulócitos, onde haverá diferentes graus de pancitopenia e reticulocitopenia; um mieolograma com hipocelularidade global e biópsia de medula com hipoplasia intensa.

Em vigência do diagnóstico pode-se classificar a AA em grave, moderada ou leve. A AA grave encaixa-se quando há 2 itens dos 3 a seguir : Neutrófilos < 0,5 x 109 /; Plaquetas < 20 x 109 /1 Reticulócitos < 20 x 109 /l ou Medula óssea com celularidade < $25 \%$, ou $25 \%$ a $50 \%$ com $<30 \%$ de células hematopoiéticas residuais mais neutrófilos < $0,2 \times 109$ /1. A AA moderada enquadra- se com o quadro de medula óssea com celularidade $<25 \%$, ou $25 \%$ a $50 \%$ com $<30 \%$ de células hematopoiéticas residuais. E a AA leve são os pacientes que não preenchem os critérios acima.

O diagnóstico diferencial e a procura pela causa da AA fazem parte do protocolo de manejo da AA. A pesquisa por sorologias para infecções virais deve se feita, então, na busca por possíveis fatores causais. No presente caso, todas as sorologias foram negativas. $\mathrm{O}$ que se conclui é que o fator causal no presente caso é a infecção pelo Herpes vírus ocorrida um mês antes, causando paralisia hemifacial direita, com quadro iniciado por otalgia, denominada Paralisia de Bell, que atingiu o VII par craniano.

Quanto ao diagnóstico diferencial, a anemia megaloblástica deve ser cogitada, pois também pode cursar com pancitopenia, mas terá os índices de vitamina B12 e/ou ácido fólico diminuídos. Sendo que no presente caso a dosagem estava normal.

Imunofenotipagem por citometria de fluxo auxilia ainda no diagnóstico diferencial com hemoglobinúria paroxística noturna (HPN), que terá ainda CD55 e CD59 negativos, sendo que, no caso, a HPN foi afastada pelo teste. Radiografia simples de tórax ainda está entre os exames que auxiliam no diagnóstico diferencial, pois no timoma e na anemia de Fanconi haveria alterações; nossa paciente tem a radiografia sem alterações. Ultrassonografia de abdome pode auxiliar na busca por hepato ou esplenomegalia, porém nossa paciente tinha ultrassonografia sem anormalidades. E devido à escassez leucocitária da paciente, não foi possível concluir a investigação para Anemia de Fanconi.

Para acompanhamento e evolução, exames de função hepática e renal devem ser pedidos ao longo do tratamento, devido à toxicidade do mesmo. A paciente apresentou toxicidade hepática devido ao uso de ciclosporina, que foi interrompida nesse momento.

Em vista de tratar esses pacientes, a tipagem de HLA deve ser realizada, para busca de possíveis doadores compatíveis com o transplante de medula óssea (TMO). Caso haja doador HLA compatível, o TMO a é o tratamento de escolha, especialmente para pacientes com menos de 40 anos e com poucas ou sem transfusões prévias. A taxa de resposta ao TMO é de $80 \%$ a $90 \%$. Porém, a mortalidade tende a aumentar com a idade 
e a sobrevida de pacientes maiores de 40 anos com TMO é, em geral, de 50\%. Assim, existe tendência natural de se considerar o TMO como tratamento de primeira linha apenas para pacientes com menos de 40 anos de idade. Nossa paciente, com 24 anos, com um quadro grave da doença, encaixa-se no perfil de transplante, já realizou teste de HLA e encontrou doador compatível e está no aguardo para a definição da compatibilidade.

Apenas $25 \%$ dos pacientes encontram doadores compatíveis. Por esse motivo, por ter idade avançada, ou na espera do transplante outro tratamento se faz necessário. $O$ tratamento com imunossupressores é tido como de escolha, pois o mecanismo autoimune pode acabar por suprimir a hematopoiese. O tratamento deve englobar baixa toxicidade, alta taxa de resposta e baixo risco de recidiva e complicações tardias. As drogas de escolha são corticosteroides, ciclosporina e globulina antitimocítica / antilinfocitária. A primeira linha de tratamento para AA grave é a associação de globulina com ciclosporina, nossa paciente fez esse esquema e teve que suspender a ciclosporina por toxicidade hepática.

Além disso, o tratamento hemoterápico se dá por transfusão de concentrado de glóbulos vermelhos filtrados, e as transfusões plaquetárias idealmente por aféreses.

O prognóstico desses pacientes pode piorar principalmente em vigência de infecções oportunísticas. Essa é, inclusive, a principal causa de morbidade e mortalidade. A febre pode ser a única manifestação presente, e as infecções bacterianas podem progredir rapidamente, em vista disso deve ser usado antibiótico de amplo espectro. Nossa paciente, devido neutropenia severa e prologada, vem sendo tratada para as infecções oportunistas, o que complica ainda mais o quadro geral.

\section{Conclusão}

$\mathrm{Na}$ vigência do diagnóstico de AA necessitamos começar imediatamente o tratamento, em vista que os pacientes raramente evoluem para uma remissão completa da doença, portanto o diagnóstico precoce seguido de tratamento auxiliam no melhor prognóstico dos casos. Na possibilidade da realização de TMO com doador HLA idêntico há $80 \%$ de possibilidade de cura. Os resultados com transplantes não consanguíneos porém, são limitados e a sobrevida é, em geral, inferior a $40 \%$ em 3 anos. Nossa paciente segue acompanhamento ambulatorial, com pesquisa constante por possíveis infecções, no controle dos níveis de plaqueta e hemácias, mantendo uma rotina de vida voltada a prevenção de exacerbações e quadros agravantes, ao passo que aguarda por TMO que lhe trará possível cura. 


\section{Post viral aplastic anemia: Case report}

\section{Abstract}

Aplastic anemia is a chronic, rare and highly lethal disease, characterized by some degree of pancytopenia and severe hypocellularity in the bone marrow. The differential diagnosis of diseases that also occur with pancytopenia is indispensable. As well, the search for causal factor. Treatment is with bone marrow transplantation when patients are under 40 years and have donor HLA compatible or imussupressores. The prognosis is on and tends to be better when the bone marrow transplant is performed with HLA identical donor.

Keywords: pancytopenia ; coagulation disorder; aplastic anemia 


\section{Referências}

SOUSA, Adriana Martins de. Fatores prognósticos para sobrevivência após transplante de medula óssea em portadores de anemia aplástica. / Adriana Martins de Sousa. -- 2012. xvii, 113 f. : il. ; tab. ; Graf.

PITA, MT; LOGGETTO, SR; SEBER, A; MALUF, EMCP; LOTÈRIO, HA; MARQUES, HJH; BIGONHA, JG; CARNEIRO; JDA. Tratamento da anemia aplástica Sociedade Brasileira de Hematologia e Hemoterapia. Projeto Diretrizes. 2008.

LOPES, Antonio Carlos, ed. - Tratado de Clínica médica. São Paulo, Roca, 2006. 3v. volume 2. ilus. ISBN-10: 85-7241-601-3. 